\title{
ENHANCING HEAT DISSIPATION FROM THE SURFACE OF A SPHERE BY FORCED OSCILLATIONS
}

\author{
Prahlad Kulkarni \\ Department of Mechanical EngineeringR V College of EngineeringBangalore, India
}

\begin{abstract}
The main objective of this paper is to enhance the rate of heat dissipation from the surface of a sphere in the absence of cross flow or external flow. This is achieved by making the sphere oscillate about the mean position sinusoidally so that the forced convective heat transfer coefficient which depends on the velocity of the sphere also varies sinusoidally between a minimum and a maximum value whose average value computed over half cycle is found to be greater than that computed for a still sphere (without oscillation), thereby increasing the overall heat dissipation rate. The effectiveness of the model is measured and its variation with parameters like amplitude and frequency of oscillation and diameter of the test sphere are analysed using respective graphs.
\end{abstract}

\section{KEY WORDS}

Forced Oscillations, Effectiveness, Heat Dissipation Rate, Oscillation of Sphere

\section{INTRODUCTION}

It is known that a flow around an object like a sphere increases the rate of heat dissipation compared to natural convection under similar conditions, but the objective of this paper is to increases the rate of heat transfer in the absence of an external flow, in conditions where any kind of external flow is not possible. This can be achieved by making the sphere oscillatesinusoidally with time about any symmetric plane passing through the centre of the sphere, thus by doing this the velocity of the sphere also varies sinusoidally with time, thus the forced convective heat transfer coefficient which depends upon Reynolds number (Re) which intern depends upon the velocity of sphere also varies with time having a maximum and a minimum value for each cycle of oscillation. It was found out from the analysis that the heat transfer coefficient for the oscillating sphere averaged over half cycle of oscillation was greater than the heat transfer coefficient calculated for a still sphere under similar conditions, and the other half cycle has similar effects with respect to heat dissipation, thereby making the proposed model effective within a range of amplitudes

\section{PROCEDURE}

2.1 First a mathematical formulation is done to establish relations for rate of heat transfer with and without oscillation for a general sphere, then a test sphere with default dimensions ,frequency and amplitude of oscillation is used to determine the effectiveness and to show that it is greater than unity

DOI : 10.14810/ijmech.2015.4301 
International Journal of Recent advances in Mechanical Engineering (IJMECH) Vol.4, No.3, August 2015

2.2 Next the variation of heat transfer coefficient (h),(for the oscillating sphere) with time is shown graphically for half of the time period(T/2) of oscillation and the average value is also plotted. $\mathrm{h}$ value for still sphere(without oscillation) is also plotted in the same graph for comparison,

2.3 Variation of $\mathrm{h}$ value (for oscillating sphere) with time is plotted for different values of amplitude of oscillation and a logical conclusion is made.

2.4 The variation of cut-off amplitude (below which the model is not effective) is tabulated and plotted for different values of the frequency of oscillation.

2.5 The variation of the effectiveness of the model for different frequency and for different amplitudes of oscillation are plotted and a logical conclusion is made

2.6 The model is used to analyse the effect of the diameter of the sphere on the rate of heat transfer and thus the variation of effectiveness with sphere diameter is shown

\section{MATHEMATICAL FORMULATION}

Consider each point on the sphere oscillating with simple harmonic motion $\mathrm{a}=$ Amplitude of oscillation

$\omega=$ Angular frequency

$N u_{D}=$ Nusselt number across the diameter of the sphere

$R e_{D}=$ Reynolds number of the flow across the sphere

$\operatorname{Pr}=$ Prandtl number

$\mu=$ Dynamic viscosity of air

$\rho=$ Density of air

$\mathrm{D}=$ Diameter of the sphere

$\mathrm{k}=$ Thermal conductivity of air

$\mathrm{h}=$ Heat transfer coefficient

For simplicity let the displacement of each particle be represented by

$$
x=-\operatorname{acos}(\omega t)
$$

The above SHM equation is considered because the velocity must be zero at $\mathrm{t}=0$,

Differentiating with respect to $t$

$$
\frac{d x}{d t}=\operatorname{a\omega sin}(\omega t)=\text { velocity } v(t)
$$

From literature it has been well established that for forced convection around a sphere(Whitaker correlation)

$$
N u_{D}=2+\left(0.4 R e_{D}^{0.5}+0.06 \operatorname{Re}_{D}^{(2 / 3)}\right) \operatorname{Pr}^{0.4}\left(\frac{\mu}{\mu_{s}}\right)^{0.25}
$$


Reynolds number:

$$
R e_{D}(t)=\frac{\rho v(t) D}{\mu}
$$

Substituting $R e_{D}(t)$ in the above equation we get:

$$
\mathrm{Nu}_{\mathrm{D}}(\mathrm{t})=2+\left(0.4\left(\frac{\rho v(\mathrm{t}) \mathrm{D}}{\mu}\right)^{0.5}+0.06\left(\frac{\rho v(\mathrm{t}) \mathrm{D}}{\mu}\right)^{2 / 3}\right) \operatorname{Pr}^{0.4}\left(\frac{\mu}{\mu_{\mathrm{s}}}\right)^{0.25}
$$

But $\mathrm{v}$ is a function of time, replacing in Reynolds number formulae,

Replacing $v(t)$ in $N u_{D}$ equation we get,

$$
\begin{gathered}
\operatorname{Re}_{D}(t)=\frac{\rho a \omega \sin (\omega t) D}{\mu} \\
N u_{D}(t)=2+\left(0.4\left(\frac{\rho a \omega \sin (\omega t) D}{\mu}\right)^{0.5}+0.06\left(\frac{\rho a \omega \sin (\omega t) D}{\mu}\right)^{2 / 3}\right) \operatorname{Pr}^{0.4}\left(\frac{\mu}{\mu_{s}}\right)^{0.25}
\end{gathered}
$$

Now $\mathrm{Nu}_{\mathrm{D}}=\frac{\mathrm{hD}}{\mathrm{k}}$ thus $\mathrm{h}=\frac{\mathrm{Nu}_{\mathrm{D}} \mathrm{k}}{\mathrm{D}}$

$$
\begin{gathered}
h(t)=\frac{N u_{D}(t) k}{D} \\
\frac{h(t)=k\left(2+\left(0.4\left(\frac{\rho a \omega \sin (\omega t) D}{\mu}\right)^{0.5}+0.06\left(\frac{\rho a \omega \sin (\omega t) D}{\mu}\right)^{2 / 3}\right) \operatorname{Pr}^{0.4}\left(\frac{\mu}{\mu_{s}}\right)^{0.25}\right.}{D}
\end{gathered}
$$

Thus the rate of heat transfer from the sphere to air is

$$
\frac{d Q(t)}{d t}=h(t) A\left(T_{S}-T_{\infty}\right)
$$

Thus the net heat transferred per quarter time period can be determined by integrating $Q(t)$ from 0 to $\mathrm{T} / 4$ Where $\mathrm{T}$ is the time period

$$
\begin{aligned}
& \int_{0}^{\mathrm{Q}} \mathrm{dQ}(\mathrm{t})=\int_{0}^{\left(\frac{\mathrm{T}}{4}\right)}\left(\mathrm{h}(\mathrm{t}) \mathrm{A}\left(\mathrm{T}_{\mathrm{S}}-\mathrm{T}_{\infty}\right)\right) \mathrm{dt} \text {, Let }\left(\mathrm{T}_{\mathrm{S}}-\mathrm{T}_{\infty}\right)=\Delta \mathrm{T} \\
& \mathrm{Q}=\mathrm{k} \int_{0}^{\left(\frac{\mathrm{T}}{4}\right)} \frac{\left(\left(2+\left(0.4\left(\frac{\rho \mathrm{a} \omega \sin (\omega \mathrm{t}) \mathrm{D}}{\mu}\right)^{0.5}+0.06\left(\frac{\rho \mathrm{a} \omega \sin (\omega \mathrm{t}) \mathrm{D}}{\mu}\right)^{\frac{2}{3}}\right) \operatorname{Pr}^{0.4}\left(\frac{\mu}{\mu_{\mathrm{s}}}\right)^{0.25}\right) \mathrm{A} \Delta \mathrm{Tdt}\right.}{\mathrm{D}}
\end{aligned}
$$

Net heat transfer per cycle can be obtained by multiplying $Q$ by 4 $\mathrm{Q}_{\mathrm{PC}}=4 \mathrm{Q}$ Also average Power of heat transfer can be obtained by

$\mathrm{Q}_{\mathrm{avg}}=\frac{\mathrm{Q}_{\mathrm{PC}}}{\mathrm{T}} \frac{=\omega \mathrm{Q}_{\mathrm{PC}}}{2}$ 


$$
Q_{\text {avg }}=\underset{\pi D}{2 \omega k} \int_{0}^{\left(\frac{T}{4}\right)}\left(\left(2+\left(0.4\left(\frac{\rho a \omega \sin (\omega t) D}{\mu}\right)^{0.5}+0.06\left(\frac{\rho a \omega \sin (\omega t) D}{\mu}\right)^{\frac{2}{3}}\right) \operatorname{Pr}^{0.4}\left(\frac{\mu}{\mu_{s}}\right)^{0.25}\right) A \Delta T d t\right.
$$

Thus the average power of heat transfer with oscillation is $Q_{a v g}=P_{f}$

Power of Heat Transfer without Oscillation ( $\mathrm{f}=0$ )

In this case Grashoff number is to be determined,

$$
G r_{D}=\frac{g \beta\left(T_{S}-T_{\infty}\right) D^{3}}{v^{2}}
$$

Properties are evaluated at film temperature

$$
\mathrm{T}=\frac{\mathrm{T}_{\mathrm{s}}+\mathrm{T}_{\infty}}{2}
$$

$\beta=1 / \mathrm{T},(\mathrm{T}$ in kelvin, $\mathrm{K})$

$\operatorname{Pr}$ is also noted down at $T$

From literature, nusselt number for natural convection for sphere (churchill correlation)

$$
\begin{aligned}
& N u_{D}=2+0.589 R a_{D}^{0.25} \\
& \left.\left[1+(0.469 / \operatorname{Pr})^{9 / 16}\right)\right]^{4 / 9}
\end{aligned}
$$

Now $\mathrm{Nu}_{\mathrm{D}}=\frac{\mathrm{hD}}{\mathrm{k}}$ thus $\mathrm{h}=\frac{\mathrm{Nu}_{\mathrm{D}} \mathrm{k}}{\mathrm{D}}$, also

$\mathrm{Ra}=\mathrm{GrPr}$

Power of heat transfer without oscillations is $\mathrm{P}_{\mathrm{f}=0}=\mathrm{hA} \Delta \mathrm{T}$

Effectiveness of the Model:

Effectiveness is the measure of how effective the model is, which is technically a ratio of power of heat transfer with oscillation to that of without oscillations

$$
\varepsilon=\frac{P_{f}}{\mathrm{P}_{\mathrm{f}=0}}
$$

\section{RESULTS AND DISCUSSION}

\subsection{Model Effectiveness Calculation}

In this section we calculate the effectiveness for a specimen values

$\mathrm{D}=20 \mathrm{~cm}, \mathrm{f}=100 \mathrm{hz}, \mathrm{a}=0.8 \mathrm{~cm}$ 
International Journal of Recent advances in Mechanical Engineering (IJMECH) Vol.4, No.3, August 2015

\section{Power of heat transfer with oscillation:}

$\omega=2 \pi \mathrm{f}=628.318 \mathrm{~Hz}, \quad \mathrm{x}=-\operatorname{acos}(\omega t)=$

$-0.008 \cos (628.318 t)$

$T_{S}=60^{\circ} \mathrm{C}=333 \mathrm{~K}, T_{\infty}=30^{\circ} \mathrm{C}=303 \mathrm{~K}, \mu \mathrm{s}=2.203^{*} 10^{-5} \mathrm{~kg} / \mathrm{m} / \mathrm{s}$

AT $303 \mathrm{~K}$, For air, $\rho=1.166 \mathrm{~kg} / \mathrm{m}^{3} \mathrm{k}=0.0264 \mathrm{~W} / \mathrm{mK} . \mu=1.87 * 10^{-5} \mathrm{~kg} / \mathrm{m} / \mathrm{s}, \operatorname{Pr}=0.712$

, velocity $v(t)=a \omega \sin (\omega t)=5.026 \sin (628.318 t)$

$\operatorname{Re}_{D}(t)=\frac{\rho v(t)}{\mu} D=6.2677 * 10^{4} \sin (628.318 t)$

Time period $=2 \pi=0.01 \mathrm{~s}$

$\omega$

$\mathrm{Q}=\frac{2 \omega k A \Delta T}{\pi D} *\left[\int_{0}^{0.0025} 2 d t+\operatorname{Pr}^{0.4}\left(\frac{\mu}{\mu_{s}}\right)^{0.25}\left[\int_{0}^{0.0025} 100.14 \sin ^{0.5}(200 \pi t) d t+\int_{0}^{0.0025} 94.679 \sin ^{\frac{2}{3}}(200 \pi t) d t\right]\right.$

$\mathrm{Q}=199.02\left[\int_{0}^{0.0025} 2 d t+0.8379 \int_{0}^{0.0025} 100.14 \sin ^{0.5}(200 \pi t) d t+\int_{0}^{0.0025} 94.679 \sin ^{\frac{2}{3}}(200 \pi t) d t\right.$

$\mathrm{Q}=199.02[0.005+0.8379(0.190955+0.1687)] \mathrm{w}$

$\mathrm{Q}=60.98 \mathrm{w}$

Thus $P_{f}=60.98 \mathrm{w}$

\section{Power of heat transfer without oscillation:}

$\mathrm{T}=(30+60) / 2=45^{\circ} \mathrm{C}, \beta=1 /(273+45)=3.14465^{*} 10^{-3}$

At $\mathrm{T}, \mathrm{v}=17.4525 * 10^{-6} \mathrm{~m}^{2} / \mathrm{s}, \mathrm{k}=0.02745 \mathrm{~W} / \mathrm{mK}$

$G r_{D}=\left(9.81 * 3.14465 * 30 * 0.2^{\wedge} 3 / 1000 * 304.589 * 10^{-12}\right)$ 


$$
\begin{aligned}
& G r_{D}=2.43 * 10^{7}, \mathrm{Pr}=0.7105 \\
& \mathrm{Ra}_{\mathrm{D}}=G r_{D} * \operatorname{Pr}=1.7265 * 10^{7} \\
& N u_{D}=2+0.589 *\left(1.7265^{*} 10^{7}\right)^{0.25} \\
& N u_{D}=31.2958 \\
& \mathrm{~h}=(31.3 * 0.02745 / 0.2)=4.2959 \mathrm{~W} / \mathrm{m}^{2} \mathrm{~K} \\
& P_{f=0}=4.2959 * 4 \pi * 0.1 * 0.1 * 30 \\
& P_{f=0}=16.19
\end{aligned}
$$

Thus effectiveness $=\varepsilon=P_{f} \quad=60.98=3.7668$

$$
P_{f=0} \quad 16.19
$$

Thus in this specimen calculation heat transfer from with oscillation is 3.7668 times that of without oscillation

\subsection{Variation of heat transfer coefficient (h) with time}

$h(t)=0.132\left(2+83.914 \sin ^{0.5}(200 \pi t)+79.3327 * \sin ^{\frac{2}{3}}(200 \pi t)\right.$

The below figure shows the time variation of $\mathrm{h}$ with and without oscillation for half time period (T/2),(0-0.005)s

(h in $\mathrm{W} / \mathrm{m}^{2} \mathrm{~K}$ )

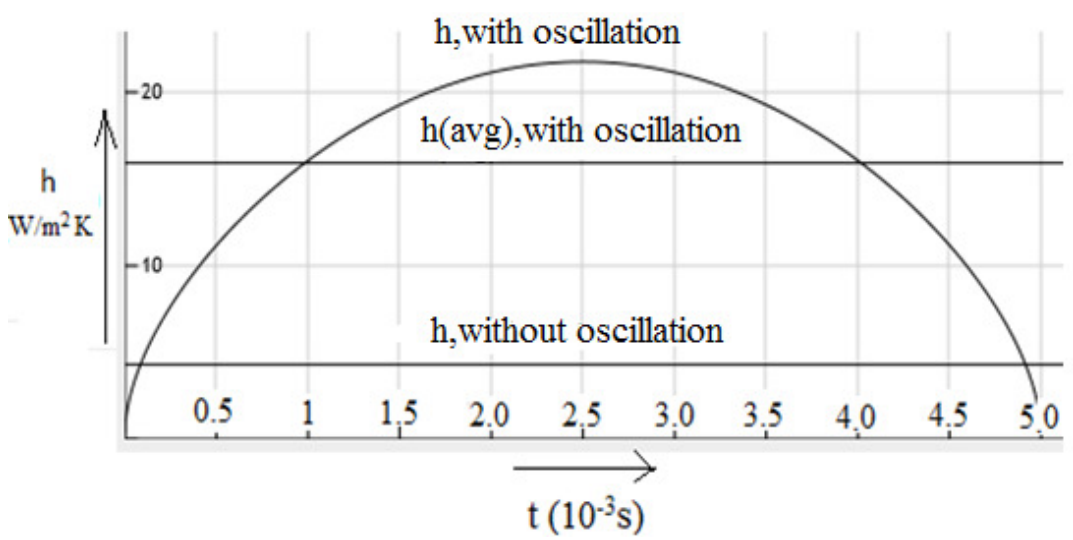

Figure1. Variation of heat transfer coefficient (h) with time

It can be inferred from the above graph that $\mathrm{h}$ for the oscillating sphere increases from zero to a maximum value and then decreases to zero and its average value is greater than that of the still sphere thus by proving that the proposed model is effective $t\left(10^{-3} \mathrm{~s}\right)$ 


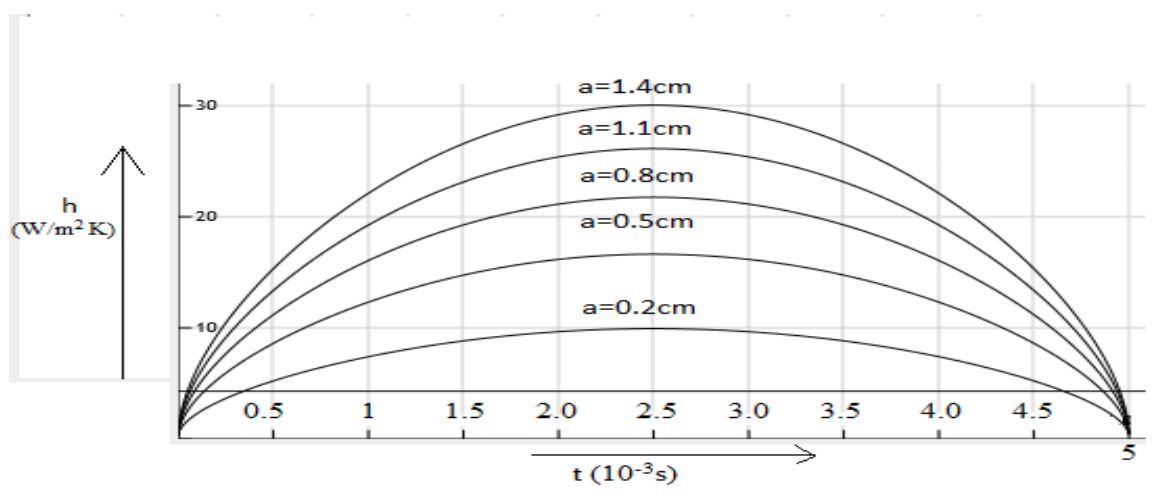

Figure 2.Variation of $\mathrm{h}$ with time for different amplitudes

It can be inferred from the above graph that as amplitude of oscillation increases the curve shifts up and the average $h$ value also increases, thus the effectiveness increases as amplitude increases.

\subsection{Cut-offAmplitude $\left(A_{c}\right)$}

This is the least amplitude valve below which the model is not effective, its value changes for different values of applied frequency, and it can be obtained by equating $P_{f}=P_{f=0}$

Thus for $100 \mathrm{~Hz}$ let cut-off amplitude be $\mathrm{a}_{\mathrm{c}}$

$P_{f}=199.02\left[\int_{0}^{0.0025} 2 d t+938.178 \sqrt{ } a \int_{0}^{0.0025} \sin ^{0.5}(200 \pi t) d t+1981.86 a^{2 / 3} \int_{0}^{0.0025} \sin ^{\frac{2}{3}}(200 \pi t) d t\right]$

$P_{f}=199.02\left(0.005+1.789 \sqrt{a}+0.164 a^{2 / 3}\right) \mathrm{w}$

$P_{f=0}=16.19 \mathrm{w}$

Equating the two, $0.0763486=1.789 \sqrt{a}+3.533 a^{2 / 3}$

After solving

$\mathrm{a}_{\mathrm{c}}=0.0719 \mathrm{cmor} 0.719 \mathrm{~mm}$

Table1.frequency vs cut-off amplitude

\begin{tabular}{|l|l|}
\hline Frequency f $(\mathrm{Hz})$ & Cut-offamplitude(mm) \\
\hline 60 & 4.57 \\
\hline 70 & 2.595 \\
\hline 80 & 1.595 \\
\hline 90 & 1.0425 \\
\hline 100 & 0.719 \\
\hline
\end{tabular}




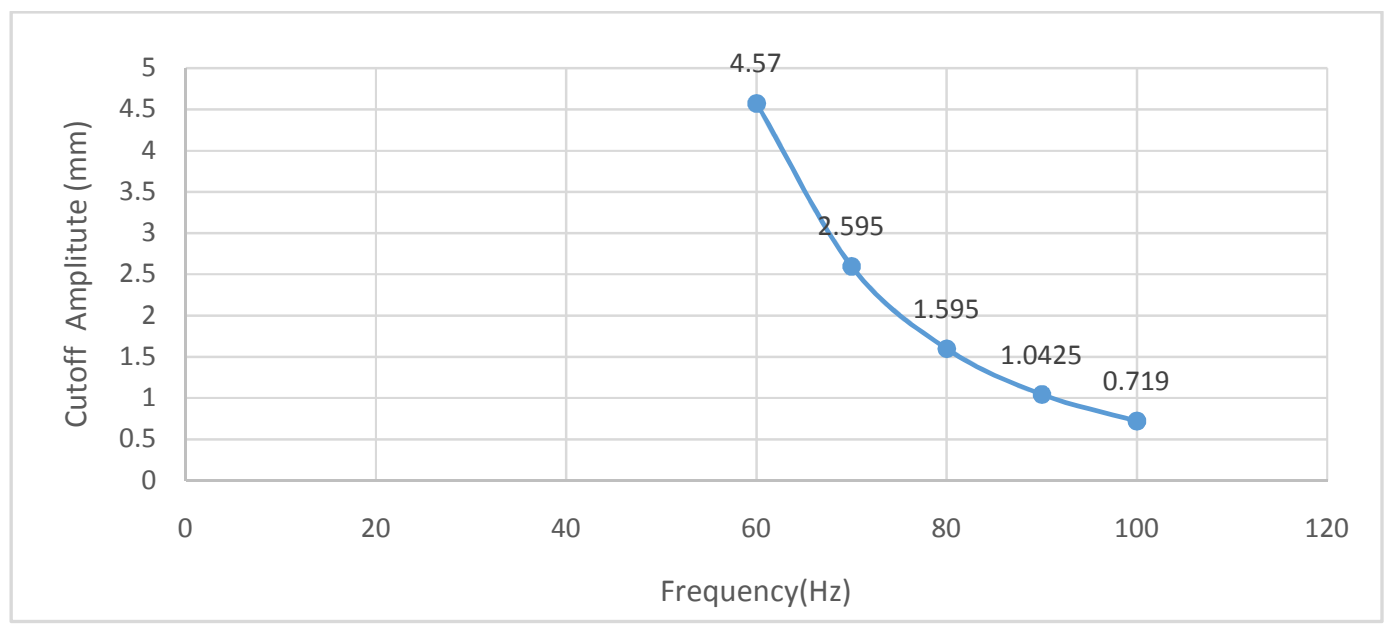

Figure3.Cutoff amplitude vs frequency of oscillation

It can be inferred from the graph that as applied frequency increases the amplitude can be decreased to a lesser amplitude in the effective region

\subsection{Effectiveness Vs Frequency}

The following results were calculated at amplitude $=0.8 \mathrm{~cm}$ and $20 \mathrm{~cm}$ diameter ,the variation of effectiveness with frequency is shown in fig 4

Table2. Frequency Vs Effectiveness

\begin{tabular}{|l|l|}
\hline Frequency $\mathrm{f}(\mathrm{Hz})$ & Effectiveness $\varepsilon$ \\
\hline 60 & 1.361 \\
\hline 70 & 1.86 \\
\hline 80 & 2.431 \\
\hline 90 & 3.055 \\
\hline 100 & 3.76 \\
\hline
\end{tabular}

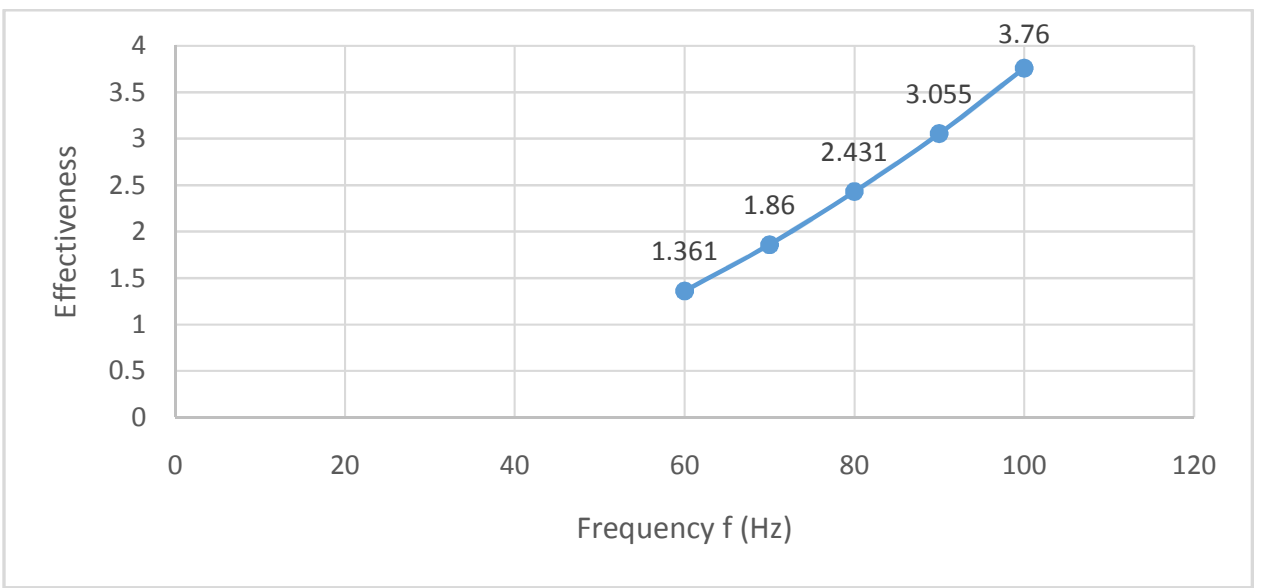

Figure4.Effectiveness vs Frequency 
International Journal of Recent advances in Mechanical Engineering (IJMECH) Vol.4, No.3, August 2015

It can be inferred from the graph that as frequency increases the Effectiveness also increases

\subsection{Effectiveness Vs Amplitude}

The following were calculated at frequency $100 \mathrm{~Hz}$ and $20 \mathrm{~cm}$ diameter

The variation of effectiveness vs amplitude is shown in fig 5 and tabulated in table 3

Table3. Amplitude vs Effectiveness

\begin{tabular}{|l|l|}
\hline Amplitude(mm) & Effectiveness \\
\hline 2 & 1.7349 \\
\hline 5 & 2.88 \\
\hline 8 & 3.76 \\
\hline 11 & 4.5178 \\
\hline 14 & 5.1884 \\
\hline
\end{tabular}

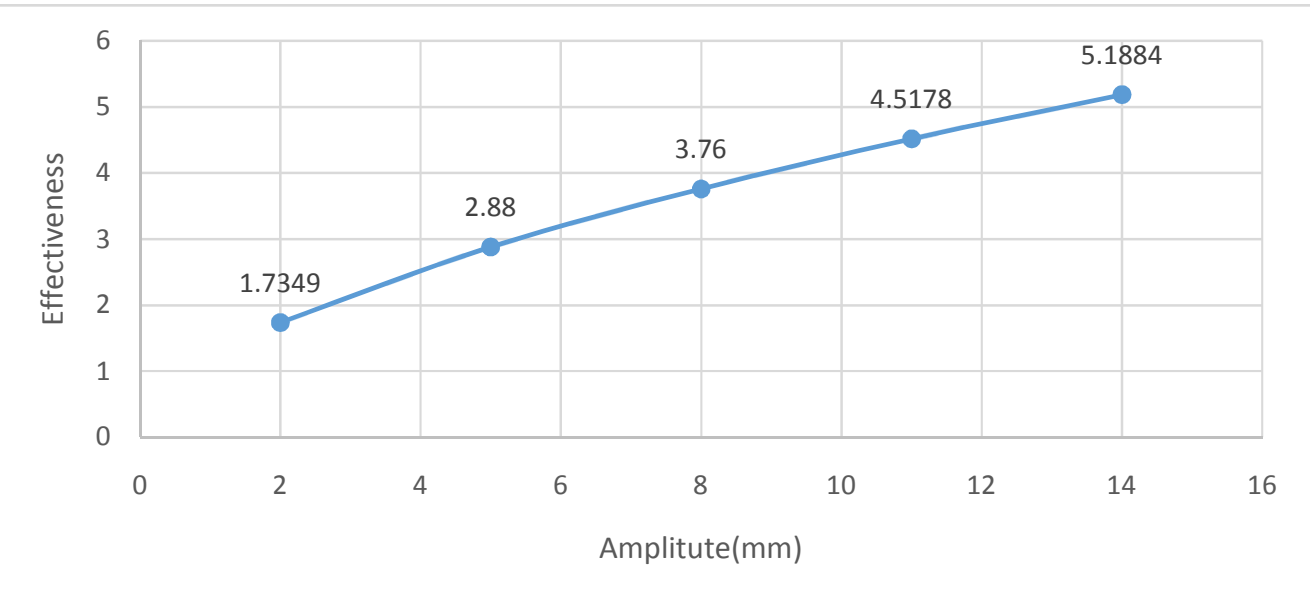

Figure 5.Effecftiveness vs Amplitude

It can be inferred from the graph that as amplitude increases the effectiveness also increases $\left(a>a_{c}\right)$

\subsection{Effectiveness vs Diameter of sphere}

The effectiveness for different diameters of the test sphere are computed and tabulated in table 4 The following calculations were made at Frequency $=100 \mathrm{~Hz}$ and amplitude $=0.8 \mathrm{~cm}$

Table 4. Effectiveness Vs Diameter Of The Test Sphere

\begin{tabular}{|l|l|l|l|}
\hline Diameter $(\mathrm{Cm})$ & $P_{f=0}(\mathrm{w})$ & $P_{f}(\mathrm{w})$ & Effectiveness $\varepsilon$ \\
\hline 10 & 5.025 & 20.624 & 4.1042 \\
\hline 15 & 9.939 & 38.86 & 3.9098 \\
\hline 20 & 16.19 & 60.99 & 3.7671 \\
\hline 25 & 23.696 & 86.58 & 3.6537 \\
\hline 30 & 32.374 & 115.33 & 3.624 \\
\hline
\end{tabular}




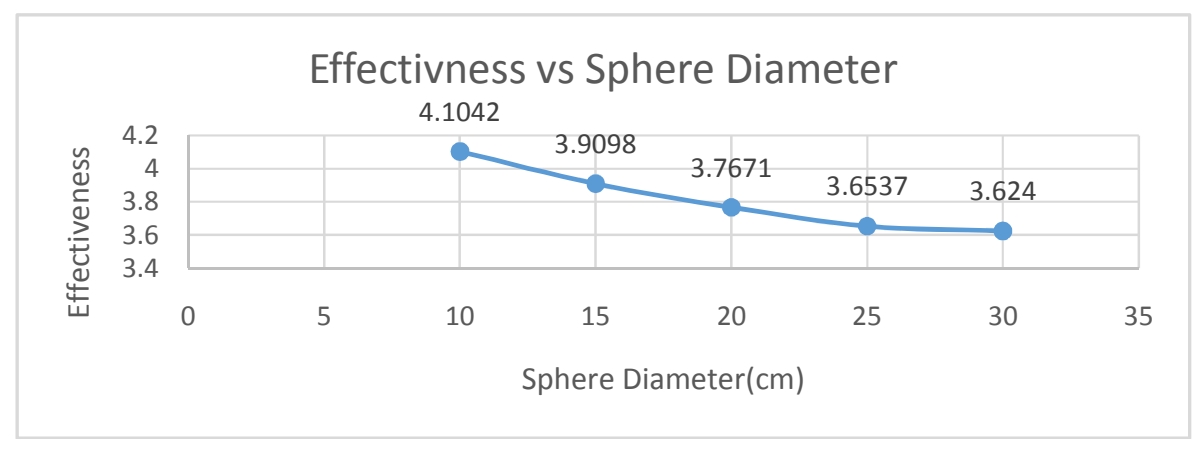

Figure 6.Effectiveness vs Diameter of the test Sphere

It can be inferred from the above graph that the model is more effective for smaller spheres

\section{CONCLUSION}

Thus a model to enhance the rate of heat dissipation from the surface of a sphere without external flow is defined and analysed where a sphere is made to oscillate sinosudally with respect to time. Power dissipation for a still sphere and a oscillating sphere is compared and the variation of $h$ with time for both the spheres is analysed, compared and plotted. The effectiveness of the system is analysed and its dependence on various parameters like amplitude and frequency of oscillation, diameter of the sphere is analysed and the corresponding graphs are plotted.

Application: this model is not just restricted to spheres it can be applied to cylinders and plates as well by using the appropriate nusselt no correlations, and thus this model can be employed to increase heat dissipation rate without the need for a external flow forced convection, thus the system can be made compact and the body (from which heat needs to be dissipated) need not translate

\section{REFERENCES}

[1] John Lienhard IV and John Lienhard V, "A heat transfer text book " Cambridge,Massachusetts, U.S.A. , 2002

[2] Park, H.G., Gharib, M., "Experimental study of the heat convection from stationary and oscillating circular cylinder in cross flow " ASME Journal of Heat Transfer, vol. 123, pp. 51-62, 2001.

[3] Anatanarayanan, R., and Ramachandran, A. ,"Effect of vibration on heat transfer from a wire to air in parallel flow," ASME Journal of Heat Transfer, vol. 80, pp.1426-1432, 1958.

[4] Eckert, E. R. G., and R. M. Drake;"Analysis of Heat and Mass Transfer,"McGraw-Hill Book Company, New York, 1972.

[5] Abdel Latif, O.E, El-Ghnam, R.I and Ali, M., "Experimental Study of the effect of longitudinal oscillations on free convection from a heated vertical plate" Al-Azhar Engineering sixth international conference, September 2000.

\section{AUTHOR BIOGRAPHY}

Prahlad Kulkarni is currently an undergraduate Mechanical engineering student of R V College of Engineering, Bangalore, and Karnataka, India. He has presented a paper on computational mechanics at the 6th international conference on mechanical and aerospace engineering (ICMAE 2015) in Rome, Italy. His Fields of Interest include heat transfer, computational mechanics and Thermodynamics.

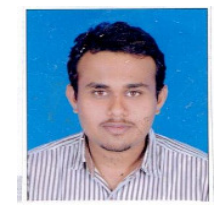

